\title{
A calculational and ultraviolet photoelectron spectroscopic study of distorted amides
}

\author{
N.H. Werstiuk, H.M. Muchall, C.D. Roy, J. Ma, and R.S. Brown
}

\begin{abstract}
Distorted amides 3,4-dihydro-2-oxo-1,4-ethanoquinoline (1a), 3,4-dihydro-2-oxo-1,4-propanoquinoline (1b), 3,3,4,5-tetrahydro-2-oxo-1,5-ethanobenzazepine (1c), and 3,3,4,5-tetrahydro-2-oxo-1,5-propanobenzazepine (1d) and the model compounds 2,N-dimethyl-acetanilide (2a), 2,N,N-trimethylaniline (3), and benzoquinuclidine (4) have been studied calculationally and with $\mathrm{He}(\mathrm{I})$ ultraviolet photoelectron spectroscopy. We find good agreement between experimentally obtained ionization energies for $\mathbf{1 b}, \mathbf{1 c}, \mathbf{1 d}, \mathbf{2 a}, \mathbf{3}$, and $\mathbf{4}$ and values calculated with HAM/3 using the equilibrium geometries obtained at the HF/6-31G** level of theory. An excellent correlation between experimental ionization energies and orbital energies from Becke3LYP/6-31+G* calculations led to the characterization of the highest occupied molecular orbitals for these compounds and for 1a, whose photoelectron spectrum could not be obtained due to its reactivity in the solid state.
\end{abstract}

Key words: distorted amides, He(I) photoelectron spectroscopy, Becke3LYP, molecular orbitals.

Résumé : Faisant appel à des calculs et à la spectroscopie photoélectronique ultraviolette He(I), on a étudié des amides déformés 3,4-dihydro-2-oxo-1,4-éthanoquinoléine (1a), 3,4-dihydro-2-oxo-1,4-propanoquinoléine (1b),

3,3,4,5-tétrahydro-2-oxo-1,5-éthanobenzazépine (1c) et 3,3,4,5-tétrahydro-2-oxo-1,5-propanobenzazépine (1d) ainsi que des composés modèles 2,N-diméthylacétanilide (2a), $2 N, N$-triméthylaniline (3) et benzoquinuclidine (4). On a observé un bon accord entre les énergies d'ionisation obtenues expérimentalement pour les composés $\mathbf{1 b}, \mathbf{1 c}, \mathbf{1 d}, \mathbf{2 a}, \mathbf{3 a}$ et $\mathbf{4}$ et les valeurs calculées par la méthode HAM/3 en utilisant les géométries d'équilibre obtenues au niveau HF/6-31G** de la théorie. Une excellente corrélation entre les énergies d'ionisation expérimentales et les énergies d'orbitales obtenues à l'aide de calculs Becke3LYP/6-31+G* conduit à la caractérisation des orbitales moléculaires hautes occupées de ces composés et du produit 1a dont on n'a pas pu obtenir le spectre photoélectronique à cause de sa réactivité à l'état solide.

Mots clés : amides déformés, spectroscopie photoélectronique He(I), Becke3LYP, orbitales moléculaires.

[Traduit par la rédaction]

\section{Introduction}

By studying a group of benzo-substituted bicyclic amides, Brown and co-workers showed that distorting the amide linkage away from planarity leads to a dramatic change in the basicity of the amides and their reactivities in $\mathrm{H}_{2} \mathrm{O}(1,2)$. The kinetics of hydrolysis of distorted amides 3,4-dihydro-2-oxo1,4-ethanoquinoline (1a), 3,4-dihydro-2-oxo-1,4-propanoquinoline (1b), 3,3,4,5-tetrahydro-2-oxo-1,5-ethanobenzazepine (1c), and 3,3,4,5-tetrahydro-2-oxo-1,5-propanobenzazepine (1d) were studied as a function of $\mathrm{pH}$ and it was suggested that on going from $\mathbf{1 d}$ to $\mathbf{1 a}$ the site of protonation changes from oxygen to nitrogen, giving rise to $\mathrm{N}$-protonated amides as

Received September 30, 1997.

This paper is dedicated to Professor Erwin Buncel in recognition of his contributions to Canadian chemistry.

N.H. Werstiuk, ${ }^{1}$ H.M. Muchall, ${ }^{1}$ C.D. Roy, and J. Ma. Department of Chemistry, McMaster University, Hamilton, ON L8S 4M1, Canada.

R.S. Brown. ${ }^{2}$ Department of Chemistry, Queen's University, Kingston, ON K7L 3N6, Canada.

${ }^{1,2}$ Authors to whom correspondence may be addressed. N.H.W and H.M.M.: Telephone: (905) 525-9140. Fax: (905) 522-2509. E-mail: werstiuk@ mcmaster.ca, muchall@mcmaster.ca, R.S.B.: Telephone: (613) 545-2624. Fax: (613) 545-6669. E-mail: rsbrown@ chem.queensu.ca

reactive intermediates in the case of $\mathbf{1 a}, \mathbf{1 b}$, and $\mathbf{1 c}$. Because $\mathrm{He}(\mathrm{I})$ photoelectron spectroscopy provides a way of ordering the molecular orbitals (MOs) while quantum chemical calculations can be used to calculate orbital energies and MO coefficients, the availability of these distorted amides and the model compounds 2,N-dimethylacetanilide (2a), 2,N,Ntrimethylaniline (3), and benzoquinuclidine (4) provided us with a unique opportunity to determine the impact of pyramidalizing the bridgehead nitrogen, twisting the amide linkage, and changing the ring size on the nature of the highest occupied molecular orbitals of the amides. This paper documents the results of our study.

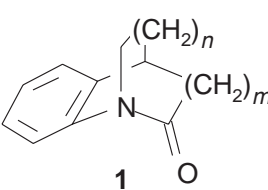

a, $m=n=1$
b, $m=1 ; n=2$
c, $m=2 ; n=1$
d, $m=n=2$

\section{Experimental}

Ultraviolet photoelectron spectroscopic studies Photoelectron (PE) spectra were acquired with a versatile,<smiles>[X]c1ccc(N(C)C(C)=O)c(C)c1</smiles><smiles>Cc1ccccc1N(C)C</smiles>
a, $\mathrm{X}=\mathrm{H}$
b, $\mathrm{X}=\mathrm{Br}$

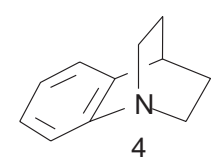


Fig. 1. $\mathrm{He}(\mathrm{I})$ ultraviolet photoelectron spectra:

(a) 2,N,N-trimethylaniline (3); (b) 3,4-dihydro-2,5-ethanoquinoline (benzoquinuclidine) (4); (c) 3,4-dihydro-2-oxo-1,4-

propanoquinoline (1b); (d) 3,3,4,5-tetrahydro-2-oxo-1,5ethanobenzazepine (1c); (e) 3,3,4,5-tetrahydro-2-oxo-1,5propanobenzazepine (1d); $(f)$ 2,N-dimethylacetanilide (2a). HAM/3 ionization energies are shown as vertical bars.
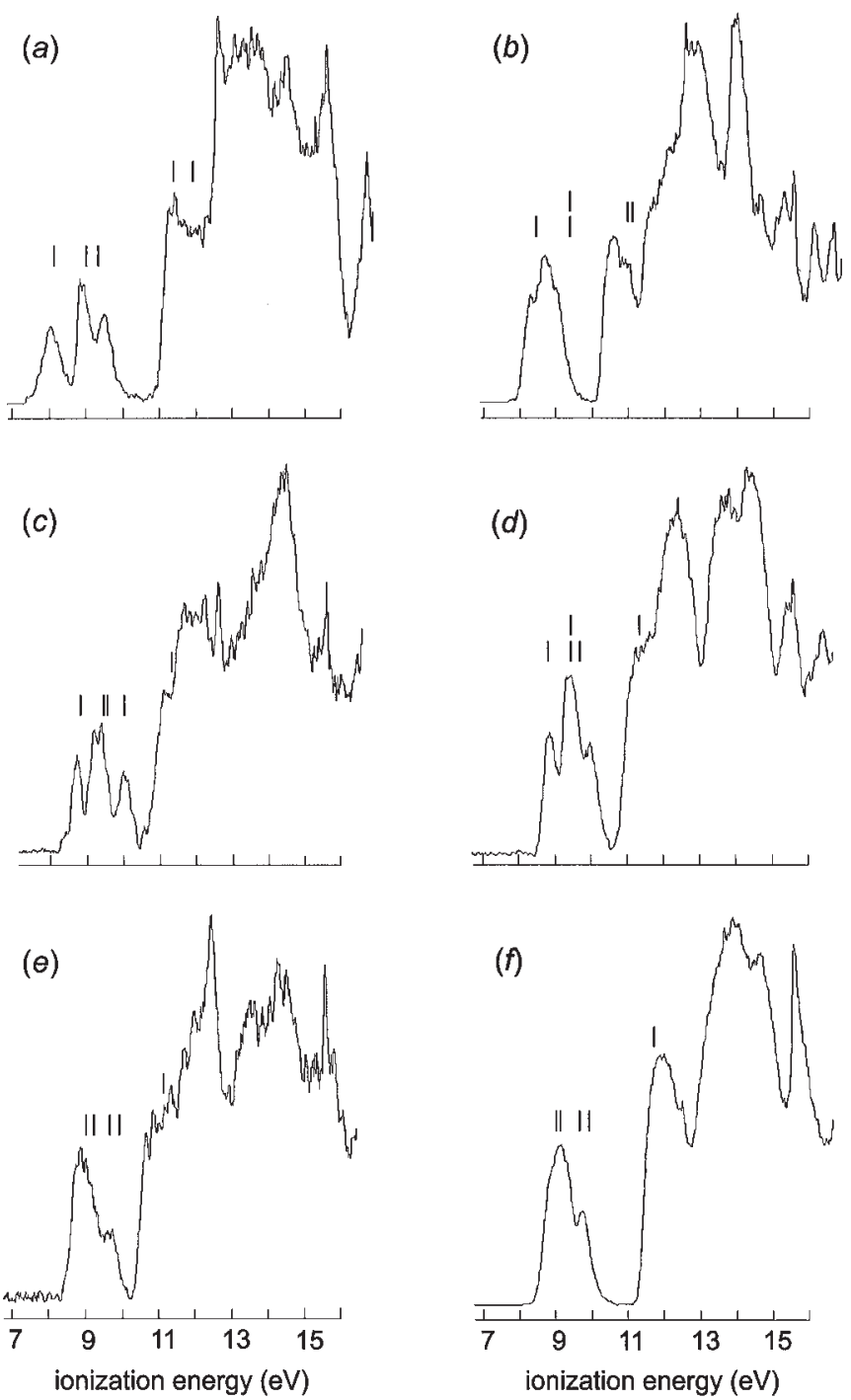

locally built spectrometer (3) designed to facilitate the handling of solids. Samples of the amides were placed in a $3 \mathrm{~mm}$ o.d. Pyrex tube - closed at one end - and inserted into the tip of a probe that could be electrically heated or cooled with circulating water. The tip of the sample tube was positioned $1 \mathrm{~cm}$ from the point of intersection with a $\mathrm{He}(\mathrm{I})$ photoionizing photon beam and the PE spectra were obtained by averaging 15-25 scans. During the acquisition of the spectra, the probe temperature was adjusted to maintain an acceptable signal level. The spectra were calibrated with $\mathrm{N}_{2}(15.6 \mathrm{eV})$ and $\mathrm{H}_{2} \mathrm{O}$ $(12.6 \mathrm{eV})$, and linearity of the scale was ensured through calibrations with $\mathrm{N}_{2}$ and acetone $(9.7 \mathrm{eV})$ performed prior to the experiments. The spectra of $\mathbf{1 b}, \mathbf{1 c}, \mathbf{1 d}, \mathbf{2 a}, \mathbf{3}$, and $\mathbf{4}$ are displayed in Fig. 1. Attempts to obtain the spectrum of 1a failed because it rapidly polymerized when handled in the solid state. The vertical ionization energies (IEs) given in Table 1 were estimated from the maxima of the bands lying between 8 and $12 \mathrm{eV}$; shoulders are indicated (sh).

\section{Calculational studies}

$\mathrm{Ab}$ initio HF (4) and Becke3LYP (5) calculations were carried out on IBM RS/6000 model $39 \mathrm{H}, 350$, and 530 computers with GAUSSIAN 92 (6) and GAUSSIAN 94 (7). The optimized equilibrium geometries of $\mathbf{1 b}-\mathbf{1 d}$ and $\mathbf{2 a}$ (geometrical structures not shown) correlated closely with the molecular structures of $\mathbf{1 b}-\mathbf{1 d}$ and $\mathbf{2 b}$ obtained with X-ray diffraction $(1,8,9)$ : the seven-membered ring of $\mathbf{1 b}$ and $\mathbf{1 c}$ adopts a chair conformation, the trimethylene bridge is oriented syn to the aromatic ring; the eight-membered ring of $\mathbf{1 d}$ adopts a crown conformation; the planar amide group of acetanilide $\mathbf{2 a}$ is nearly perpendicular to the plane of the phenyl ring. Table 2 lists calculated $\left(\mathrm{HF} / 6-31 \mathrm{G}^{* *}\right.$ and Becke3LYP/6-31+G*) and experimental $\mathrm{N}-\mathrm{C}(\mathrm{O})$ and $\mathrm{C}=\mathrm{O}$ bond lengths. HF/6-31G** optimized geometrical structures obtained with GAUSSIAN 92 were used in the semiempirical HAM/3 (10) calculations of the IEs (Table 1). PERGRA (11) was used to obtain displays of the Becke3LYP/6-31+G* MOs (which were found to compare well to HF/6-31G** eigenvectors). ${ }^{3}$

\section{Results and discussion}

The data in Table 2 show that calculations on $\mathbf{1 b}-\mathbf{1 d}$ at both the $\mathrm{HF} / 6-31 \mathrm{G}^{* *}$ and Becke3LYP/6-31+G* level of theory yield $\mathrm{N}-\mathrm{C}(\mathrm{O})$ and $\mathrm{C}=\mathrm{O}$ bond lengths that correlate well with the parameters obtained with X-ray diffraction. There is a progressive decrease in the calculated $\mathrm{N}-\mathrm{C}(\mathrm{O})$ bond lengths on going from 1a to $\mathbf{2 a}$, yet the $\mathrm{C}=\mathrm{O}$ bonds lengthen only marginally, in keeping with the results of a calculational study on formamide reported by Wiberg and Breneman (13). The results are in accord with the expectation that the interaction of the nitrogen lone pair with the carbonyl group increases through the series $\mathbf{1 a}-\mathbf{1 d}$ and $\mathbf{2 b}$. That the $\mathrm{N}-\mathrm{C}(\mathrm{O})$ bond of $\mathbf{1 d}$ is longer than the $\mathrm{N}-\mathrm{C}(\mathrm{O})$ bond of $\mathbf{2} \mathbf{b}$ (we expect that the experimental $\mathrm{N}-\mathrm{C}(\mathrm{O})$ and $\mathrm{C}=\mathrm{O}$ bond lengths of $\mathbf{2} \mathbf{b}$ and $\mathbf{2 a}$ are virtually identical) suggests that the interaction of the nitrogen lone pair with the carbonyl group of $\mathbf{1 d}$ does not occur to the same extent in this case as in $\mathbf{2 a}$ and $\mathbf{2 b}$ even though $\mathbf{1 d}$ has two 3-carbon bridges that allow the bridgehead nitrogen to become planar, a requirement for a maximal $n_{\mathrm{N}}-\pi_{\mathrm{C}=\mathrm{O}}$ interaction in an amide. It is interesting to note that the calculated $\mathrm{N}-\mathrm{C}(\mathrm{O})$ bond length of $1 \mathbf{a}$ is substantially longer than the one calculated for $\mathbf{1 b}$. Because the $\mathrm{N}-\mathrm{C}(\mathrm{O})$ and $\mathrm{C}=\mathrm{O}$ bond lengths of $\mathbf{1 b}, \mathbf{1} \mathbf{c}$, and $\mathbf{1 d}$ are reproduced with good accuracy by the calculations, we expect that the calculated $\mathrm{N}-\mathrm{C}(\mathrm{O})$ and

\footnotetext{
${ }^{3}$ A rationale for the successful application of the Koopmans' Theory-like interpretation of the orbital energies obtained at the DFT level of theory in a PE spectroscopic study of a series of carbenes has recently been provided by Arduengo and co-workers (12). It is clear that applying a uniform shift, based on the difference in calculated HOMO energy and experimental first vertical IP, to orbital energies obtained with the hybrid HF/DFT Becke3LYP method nicely reproduces the PE spectra of compounds presented here (which are vastly different from the carbenes studied by Arduengo).
} 
Table 1. HAM/3 calculated $^{a}$ and experimental vertical ionization energies (eV) of 1a-1d, 2a, 3, and 4.

\begin{tabular}{|c|c|c|c|c|c|c|c|c|c|c|c|c|c|}
\hline \multicolumn{2}{|c|}{$1 a$} & \multicolumn{2}{|c|}{$1 b$} & \multicolumn{2}{|c|}{ 1c } & \multicolumn{2}{|c|}{ 1d } & \multicolumn{2}{|c|}{$2 a$} & \multicolumn{2}{|c|}{3} & \multicolumn{2}{|c|}{4} \\
\hline Calcd. & Exp. $^{b}$ & Calcd. & Exp. & Calcd. & Exp. & Calcd. & Exp. & Calcd. & Exp. & Calcd. & Exp. & Calcd. & Exp. \\
\hline 8.76 & - & 8.79 & 8.7 & 8.76 & 8.9 & 8.97 & $9.0^{c}$ & 9.00 & $9.2^{d}$ & 8.14 & 8.0 & 8.42 & 8.3 \\
\hline 9.53 & - & 9.54 & $9.5(\mathrm{sh})$ & 9.45 & $9.4^{c}$ & 9.61 & $9.4(\mathrm{sh})$ & 9.61 & $9.2^{d}$ & 9.29 & 9.5 & 9.33 & 9.0 \\
\hline 10.10 & - & 10.03 & 10.0 & 9.67 & 10.0 & 9.91 & 9.8 & 9.87 & 9.8 & 11.35 & 11.4 & 10.96 & 10.6 \\
\hline 11.43 & - & 11.33 & 11.1 & 11.29 & 11.2 & 11.09 & 11.0 & 11.75 & 11.8 & 11.87 & 11.7 & 11.07 & 10.9 \\
\hline
\end{tabular}

${ }^{a} \mathrm{HAM} / 3 / / \mathrm{HF} / 6-31 \mathrm{G}^{* *}$ level of theory.

${ }^{b}$ Because 1a polymerized rapidly in the solid state, a spectrum could not be obtained.

${ }^{c}$ Value obtained at the maximum of the band resulting from two overlapping bands.

${ }^{d}$ Value obtained at the maximum of the broad band resulting from three overlapping bands.

Table 2. Selected experimental and calculated bond lengths $r(\AA)$ of amides $\mathbf{1 a - 1 d}, \mathbf{2 a}$, and $\mathbf{2 b}$.

\begin{tabular}{|c|c|c|c|c|c|c|}
\hline & \multicolumn{3}{|c|}{$r(\mathrm{~N}-\mathrm{C}(\mathrm{O}))$} & \multicolumn{3}{|c|}{$r(\mathrm{C}=\mathrm{O})$} \\
\hline & $\operatorname{Exp}^{a}$ & $\begin{array}{c}\mathrm{HF} / \\
6-31 \mathrm{G}^{* *}\end{array}$ & $\begin{array}{l}\text { B3LYP/ } \\
6-31+\mathrm{G}^{*}\end{array}$ & Exp. $^{a}$ & $\begin{array}{c}\mathrm{HF} / \\
6-31 \mathrm{G}^{* *}\end{array}$ & $\begin{array}{l}\text { B3LYP/ } \\
6-31+G^{*}\end{array}$ \\
\hline $1 \mathrm{a}$ & $-b$ & 1.539 & 1.467 & $-{ }^{b}$ & 1.252 & 1.206 \\
\hline $1 b$ & $1.413^{c}$ & 1.414 & 1.422 & $1.225^{c}$ & 1.189 & 1.218 \\
\hline 1c & 1.401 & 1.411 & 1.421 & 1.216 & 1.191 & 1.219 \\
\hline 1d & $1.370^{c}$ & 1.382 & 1.394 & $1.233^{c}$ & 1.198 & 1.227 \\
\hline $2 \mathbf{a}$ & $-{ }^{d}$ & 1.366 & 1.380 & ${ }^{d}$ & 1.201 & 1.230 \\
\hline $2 b$ & 1.338 & $-{ }^{e}$ & $-^{e}$ & 1.235 & $-e$ & $-^{e}$ \\
\hline
\end{tabular}

$\mathrm{C}=\mathrm{O}$ bond lengths of $\mathbf{1 a}$ are close to the experimental values, which have not yet been determined.

The computed four highest occupied MOs of amides $\mathbf{1 b}-\mathbf{1 d}$ and $2 \mathbf{a}$ comprise the electron lone pairs on nitrogen $\left(n_{\mathrm{N}}\right)$ and oxygen $\left(n_{\mathrm{O}}\right)$ as well as the two highest occupied MOs of the aromatic ring $\left(\pi_{3}\right.$ and $\left.\pi_{2}\right)$. Ionizations from these four orbitals are expected in the low-energy region of the PE spectrum and, as seen in Figs. $1 c-1 f$, bands arising from four ionizations are well separated from the main group of $\sigma$ ionizations. On going from $\mathbf{1 b}$ to $\mathbf{1 d}$ and $\mathbf{2 a}$, the spectra exhibit increasing overlap of the respective bands: while for $\mathbf{1 b}$ (Fig. 1c) all four ionizations can be assigned to individual peaks, for $\mathbf{2 a}$ (Fig. $1 f$ ) only two maxima can be given (Table 1). This is due to a shift of the first band towards higher values, which eventually leads to a complete overlap with the former second band. PE spectra of amines 3 and 4 (Figs. $1 a$ and $1 b$ ), which correspond well to those published earlier (14), possess one ionization less in this region due to the missing oxygen atom.

As seen from the data in Table 1 and the spectra displayed in Fig. 1, there is good agreement between the five lowest experimental vertical ionization energies of $\mathbf{1 b}-\mathbf{1 d}, \mathbf{2 a}, \mathbf{3}$, and 4 and their IEs calculated with HAM/3 (shown as vertical bars in Fig. 1). Yet HAM/3 does not reproduce the gradual shift of the first ionization band towards higher energies in the amide series. As this seemed to be an important point, we performed $\mathrm{ab}$ initio calculations for amides $\mathbf{1 a - 1 d}$ and $\mathbf{2 a}$ and included amine 4 in the study. While orbital energies taken from HF/6$31 \mathrm{G}^{* *}$ calculations (not given) correspond only poorly to the
Table 3. Calculated Becke3LYP/6-31+G* orbital energies $(\mathrm{eV})$ and assignments for amides $\mathbf{1 a}-\mathbf{1 d}$ and $\mathbf{2} \mathbf{a}$ as well as amine $\mathbf{4}$.

\begin{tabular}{llllll}
\hline \multicolumn{1}{c}{$\mathbf{1 a}$} & \multicolumn{1}{c}{$\mathbf{1 b}$} & \multicolumn{1}{c}{$\mathbf{1 c}$} & \multicolumn{1}{c}{$\mathbf{1 d}$} & \multicolumn{1}{c}{$\mathbf{2 a}$} & \multicolumn{1}{c}{$\mathbf{4}$} \\
\hline $6.73 n_{\mathrm{N}}{ }^{a}$ & $6.52 n_{\mathrm{N}}{ }^{b}$ & $6.58 n_{\mathrm{N}}{ }^{a}$ & $6.61 n_{\mathrm{O}}$ & $6.75 n_{\mathrm{O}}$ & $6.12 n_{\mathrm{N}}$ \\
$6.92 \pi$ & $6.96 n_{\mathrm{O}}$ & $7.06 n_{\mathrm{O}}{ }^{a}$ & $6.76 n_{\mathrm{N}}{ }^{a}$ & $6.85 n_{\mathrm{N}}{ }^{a}$ & $6.61 \pi$ \\
$7.16 \pi$ & $7.16 \pi$ & $7.15 \pi$ & $7.14 \pi$ & $7.18 \pi$ & $6.82 \pi$ \\
$7.67 n_{\mathrm{O}}$ & $7.65 \pi^{b}$ & $7.49 \pi$ & $7.51 \pi$ & $7.49 \pi$ & \\
\hline${ }^{a} n_{\mathrm{N}}-n_{\mathrm{O}}$ mixing. & & & & \\
${ }^{b} n_{\mathrm{N}}-n_{\mathrm{O}}-\pi$ mixing. & & & &
\end{tabular}

experimental data, the correlation is excellent using Becke3LYP/6-31+G* orbital energies and applying Koopmans' Theorem (15). ${ }^{3}$ For $\mathbf{1 b}-\mathbf{1 d}, \mathbf{2 a}$, and $\mathbf{4}$, all relative orbital energy differences - for the single molecules as well as those between different molecules - are represented correctly (the rather large differences in absolute values are common with Becke3LYP and are not relevant to this analysis). Calculated Becke3LYP/6-31+G* orbital energies and assignments taken from the eigenvectors are given in Table $3 .^{3}$

Graphical representations of the highest occupied molecular orbitals of amine $\mathbf{4}$ and amides $\mathbf{1 a - 1 d}$ and $\mathbf{2 a}$ determined with Becke3LYP/6-31+G* (these were checked against $\mathrm{HAM} / 3 / / \mathrm{HF} / 6-31 \mathrm{G}^{* *}$ orbitals and found to compare well) are given in Figs. 2-7, respectively. The HOMO of $\mathbf{4}$ (Fig. 2) is of $n_{\mathrm{N}}$ character with $\sigma$ electron density on the bridge $\mathrm{C}-\mathrm{C}$ bonds. HOMO- 1 and HOMO-2 are benzene-type $\pi$ orbitals $\left(\pi_{3}\right.$ and $\pi_{2}$ ). Introduction of the carbonyl group into the system leads to a loss of $\sigma-\pi$ separation: $n_{\mathrm{N}}$, which is in the plane of the aromatic ring in amine $\mathbf{4}$ and therefore does not interact with benzene $\pi$ MOs, is twisted out of this plane in amides $\mathbf{1 a - 1 d}$. The HOMO of 1a (Fig. 3) is essentially $n_{\mathrm{N}}$ with a small contribution from $n_{\mathrm{O}}$ (the torsional angle between these lone pairs estimated from the PERGRA plots is close to $\left.0^{\circ}\right)^{4}$ and electron density on the $\mathrm{C}-\mathrm{C}(\mathrm{O})$ bond; the nitrogen lone pair shows a pronounced tilt towards the benzene ring.

\footnotetext{
4 In a detailed theoretical study of the topology of the charge densities of $\mathbf{1 a}-\mathbf{1 d}$ and $\mathbf{2 a}$ with the quantum theory of atoms in molecules (16) (the results will be documented in a following paper) we have characterized the outer and inner nonbonded charge concentrations (nbcc's) of the nitrogen atoms. The torsional angles between the outer $(3,-3)$ critical points and the $\mathrm{C}-\mathrm{O}$ linkages of $\mathbf{1 a}, \mathbf{1 b}, \mathbf{1 c}$, and $\mathbf{1 d}$ are $4.2^{\circ}\left(\nabla^{2} \rho=-3.531\right)$, $45.2^{\circ}\left(\nabla^{2} \rho=-3.225\right), 50.3^{\circ}\left(\nabla^{2} \rho=-3.148\right)$, and $72.8\left(\nabla^{2} \rho=\right.$ $-2.806)$, respectively. In the case of $\mathbf{2 a}$, the nbcc's of the nitrogen atom exhibit two similar $\nabla^{2} \rho$ values of -2.553 (torsional angle $\left.92.8^{\circ}\right)$ and $-2.168\left(87.6^{\circ}\right)$.
} 
Fig. 2. HOMO to HOMO-2 of amine 4.

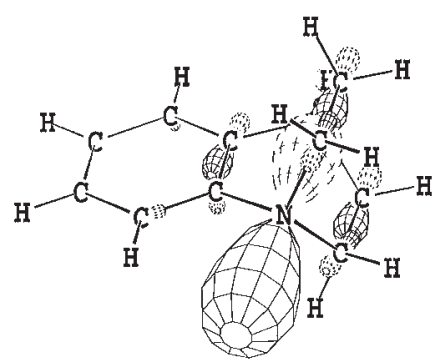

$n_{N}$

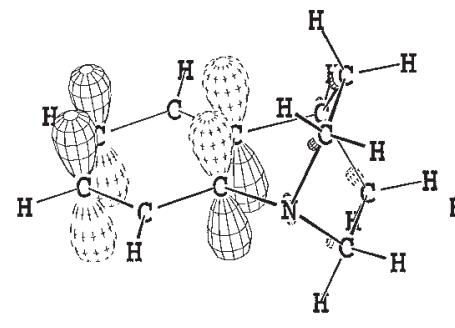

$\pi$

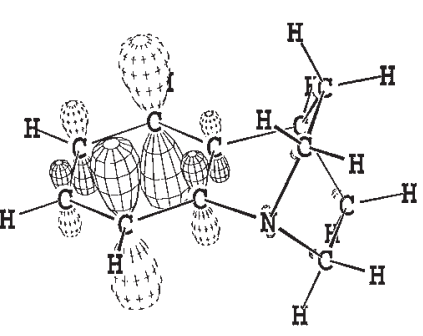

$\pi$
Fig. 3. HOMO to HOMO-3 of amide 1a.

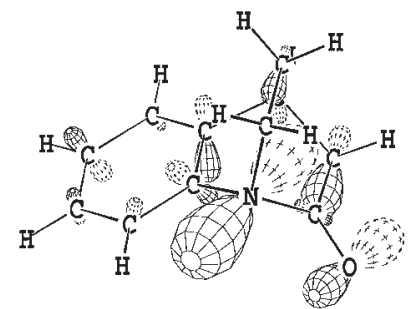

$\mathrm{n}_{\mathrm{N}}$

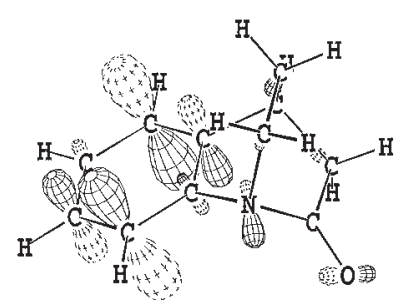

$\pi$

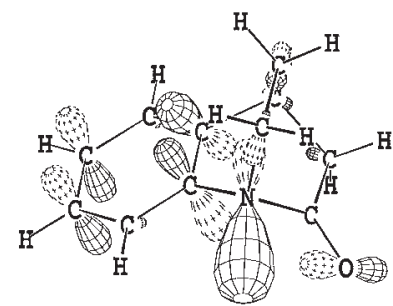

$\pi$

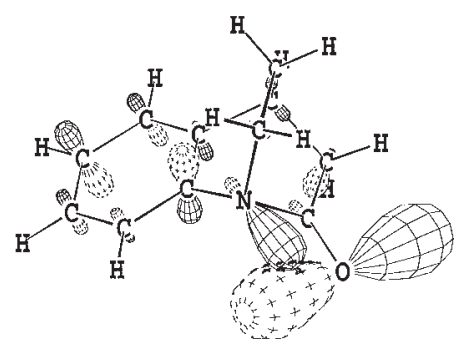

$\mathrm{n}_{\mathrm{O}}$
HOMO-1 and HOMO-2 have mainly $\pi$ character on the benzene ring, with some $n_{\mathrm{N}}$ and $n_{\mathrm{O}}$ mixing. HOMO-3 is essentially $n_{\mathrm{O}}$ (with contributions on $\mathrm{N}-\mathrm{C}(\mathrm{O})$ and $\mathrm{C}-\mathrm{C}(\mathrm{O})$ bonds). As was found for $\mathbf{1 a}$, the HOMO of $\mathbf{1 b}$ is $n_{\mathrm{N}}$ with $n_{\mathrm{O}}$ mixing, with a considerable additional amount of $\pi$ mixing (Fig. 4). The torsional angle between the lone pairs is about $40^{\circ}{ }^{4}$ HOMO- 1 is $n_{\mathrm{O}}$, as described for 1a. HOMO-2 is a benzene-type $\pi \mathrm{MO}$ while HOMO- 3 shows $\pi$ mixing with $n_{\mathrm{N}}$ and $n_{\mathrm{O}}$, as was found for the HOMO: HOMO and HOMO-3 of $\mathbf{1 b}$ seem to be two combinations of $n_{\mathrm{N}}$ and benzene $\pi$ ( $n_{\mathrm{O}}$, which is always mixed with $n_{\mathrm{N}}$, is found in different amounts according to individual interactions). For 1c, HOMO and HOMO-1 are two combinations of nearly equal amounts of $n_{\mathrm{N}}$ and $n_{\mathrm{O}}$
Fig. 4. HOMO to HOMO-3 of amide $\mathbf{1 b}$.

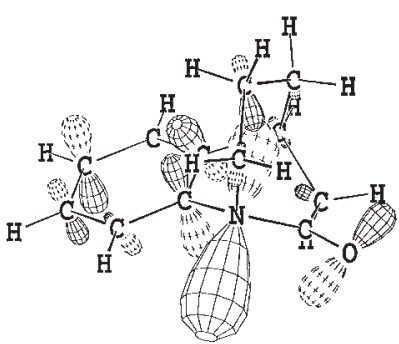

$\mathrm{n}_{\mathrm{N}}$

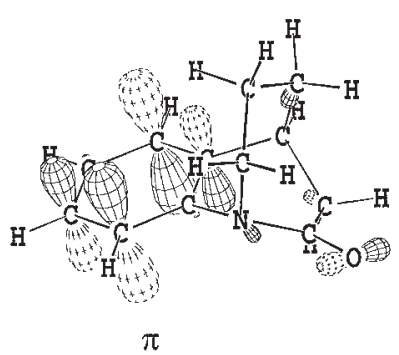

Fig. 5. HOMO to HOMO-3 of amide 1c.

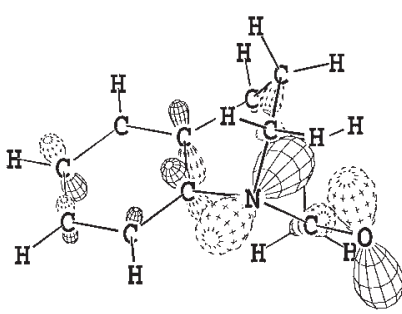

$n_{N}-n_{O}$

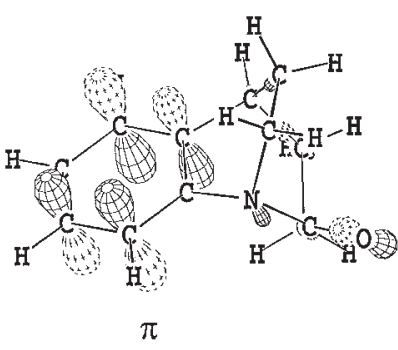

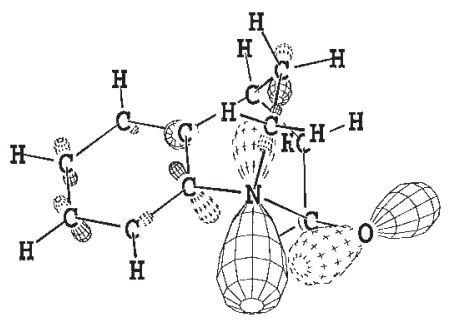

$\mathrm{n}_{\mathrm{N}}-\mathrm{n}_{\mathrm{O}}$

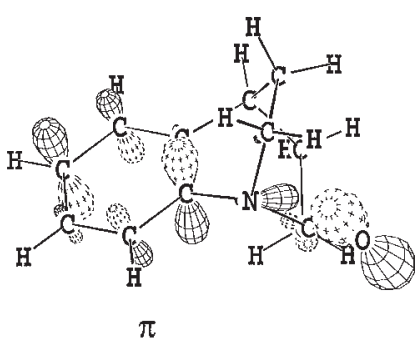

(Fig. 5). The torsional angle between $n_{\mathrm{N}}$ and $n_{\mathrm{O}}$ in the HOMO is comparable to that in the HOMO of $\mathbf{1 b}\left(40^{\circ}\right) .{ }^{4}$ As in $\mathbf{1 b}$, HOMO- 2 is of $\pi$ character; HOMO- 3 shows $\pi-n_{\mathrm{O}}$ mixing. For amides $\mathbf{1 d}$ and 2a (Figs. 6 and 7, respectively), the HOMO is $n_{\mathrm{O}}$ with pronounced coefficients along the $\mathrm{N}-\mathrm{C}(\mathrm{O})$ and $\mathrm{C}-\mathrm{C}(\mathrm{O})$ bonds. HOMO- 1 is $n_{\mathrm{N}}$ with a large contribution from $n_{\mathrm{O}}$ (the torsional angle is greater than $60^{\circ}$ ); ${ }^{4} \mathrm{HOMO}-2$ and HOMO-3 are benzene-type $\pi$ orbitals. As for 1c, HOMO-3 shows $\pi-n_{\mathrm{O}}$ mixing. It is apparent from inspection of the coefficients making up the various orbitals in Figs. 2-7 that the extensive mixing of the $n_{\mathrm{N}}, n_{\mathrm{O}}$, and $\pi$ components does not fit with our simplistic notions of an isolated amide $\pi$ system and $\mathrm{C}=\mathrm{O}$ lone pair, even in the case of $\mathbf{2} \mathbf{a}$ where such amidic resonance is allowed by the planarity of the amide unit.

The experimental (compare the spectra displayed in Fig. 1) and computational results, which are presented graphically in 
Fig. 6. HOMO to HOMO-3 of amide 1 d.

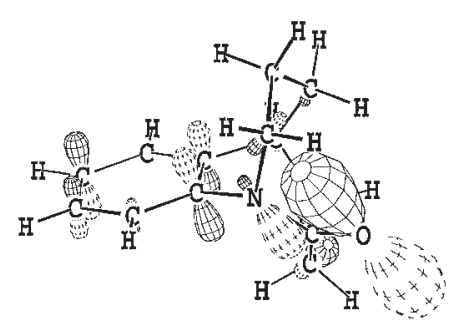

$\mathrm{n}_{\mathrm{O}}$

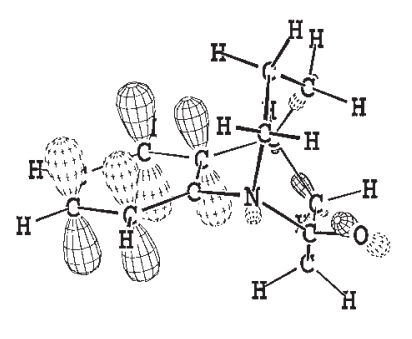

$\pi$

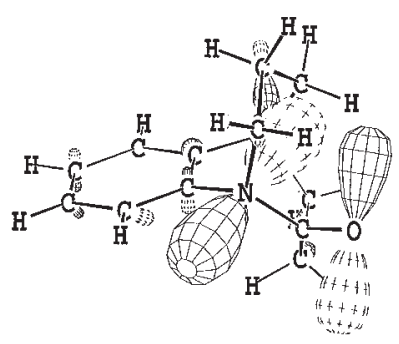

$\mathrm{n}_{\mathrm{N}}$

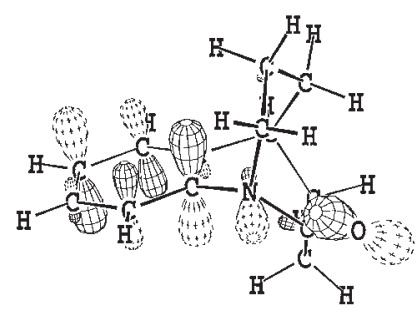

$\pi$
Fig. 7. HOMO to HOMO-3 of amide 2a.

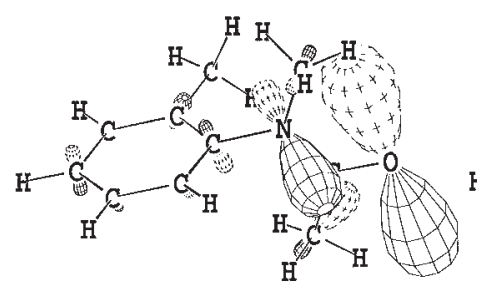

$\mathrm{n}_{\mathrm{O}}$

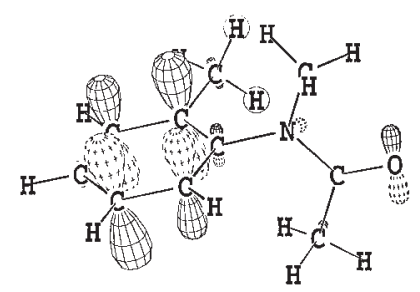

$\pi$

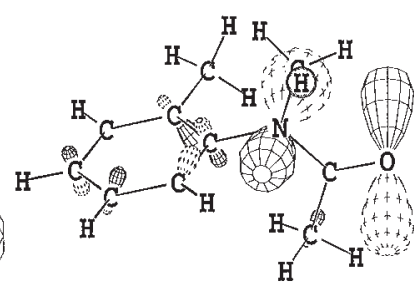

$\mathrm{n}_{\mathrm{N}}$

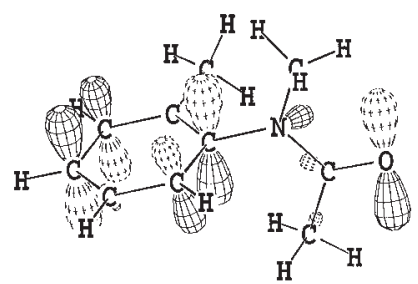

$\pi$
Fig. 8, show remarkable agreement. The high quality of the Becke3LYP calculations even allows for a prediction of the partial PE spectrum of 1a (from orbital energies given in Fig. 8). ${ }^{3}$ The first ionization should be close in energy to that of $\mathbf{2} \mathbf{a}$ with the first three bands possibly overlapping.

Figure 8 shows that, in going from amine $\mathbf{4}$ to orthogonal amide 1a, the $n_{\mathrm{N}}$ HOMO is stabilized by an inductive effect of the carbonyl group. The most striking feature obvious from Fig. 8 is the change of character of the HOMO: starting out as $n_{\mathrm{N}}$ in amine 4, it is increasingly mixed with $n_{\mathrm{O}}$ in amides $\mathbf{1 a}-\mathbf{1 c}$ and finally changes to $n_{\mathrm{O}}$ in $\mathbf{1 d}$ and $\mathbf{2 a}$. This is nicely in accordance with findings on the site of protonation in these amides (2). While $n_{\mathrm{N}}$ is more or less energetically constant in the bicyclic amide series 1a-1d, the energy of $n_{\mathrm{O}}$ changes dramatically. On going from $\mathbf{1 a}$ to $\mathbf{1 b}, n_{\mathrm{O}}$ is destabilized by $0.71 \mathrm{eV}$. There is little change in $n_{\mathrm{O}}$ energy from $\mathbf{1 b}$ to $\mathbf{1 c}$ and, again, a destabilization from $\mathbf{1 c}$ to $\mathbf{1 d}$. This can be correlated with the size of the amide ring in six-membered 1a,
Fig. 8. Progression of orbital energies $\varepsilon$ (Becke3LYP/6-31+G*) for amides 1a-1d and 2a as well as amine 4. Unassigned orbitals are of aromatic $\pi$-character.

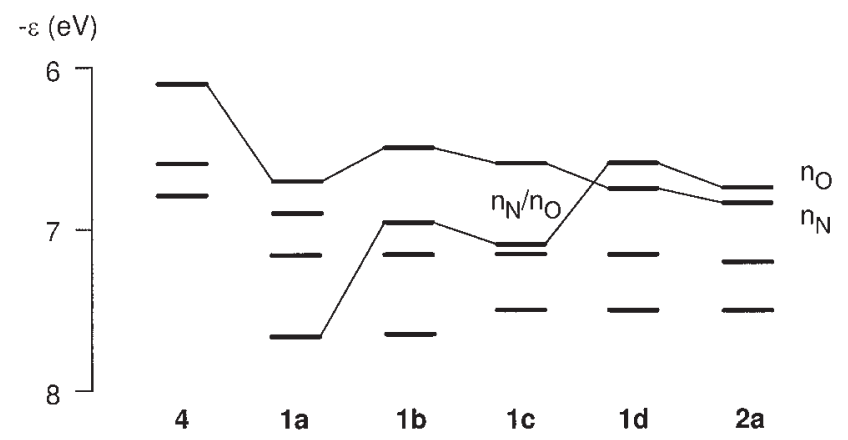

seven-membered $\mathbf{1 b}$ and $\mathbf{1 c}$, and eight-membered 1d. Such a correlation (shift of $n_{\mathrm{O}}$ due to ring expansion) in cyclic undistorted - amides was shown before (17) and was explained by recognizing that $n_{\mathrm{O}}$ contains a significant coefficient at the carbon atom in the position $\alpha$ to the carbonyl group and is therefore strongly influenced by changes in ring size. There is no such contribution in the $n_{\mathrm{N}}$ of undistorted amides, which accordingly changes little in energy upon expansion or contraction of the ring. This explanation, modified, can also be applied to the ordering of $n_{\mathrm{N}}$ and $n_{\mathrm{O}}$ in distorted bicyclic amides 1a-1d. It has to be modified for 1a because of the coefficient at the carbon atom in the position $\alpha$ to the carbonyl group in the $n_{\mathrm{N}} \mathrm{HOMO}$, which explains why this orbital is destabilized on going from 1a to 1c. Thus a more or less constant energy $n_{\mathrm{N}}$ and a gradually destabilized $n_{\mathrm{O}}$ give rise to the computed and observed changes in orbital sequence. The conspicuously high HOMO energy of $\mathbf{1 b}$ (which is confirmed by the low first IP of this amide, see Table 1) is due to an extraordinary amount of $n-\pi$ mixing.

\section{Conclusions}

By combining PE spectroscopy with calculations at HAM/3 and Becke3LYP levels of theory, we gained detailed information about the highest occupied molecular orbitals of amides $\mathbf{1 b}-\mathbf{1 d}$ and 2a. This allowed the corresponding MOs of $\mathbf{1 a}$ and its PE spectrum, which could not be obtained experimentally due to the extreme reactivity of $\mathbf{1 a}$ in the solid state, to be predicted with certainty. Amide $\mathbf{1 b}$ exhibits an unusually large degree of $n-\pi$ mixing with the benzene ring. While the HOMO of $1 \mathbf{a}$ is essentially $n_{\mathrm{N}}$, destabilization of the $n_{\mathrm{O}}$ orbital as the ring size increases leads to a HOMO of $n_{\mathrm{O}}$ character in the case of $\mathbf{1 d}$.

\section{Acknowledgments}

We gratefully acknowledge the use of the IBM SP2 computer at Queen's University granted under the auspices of an IBM Canada - Queen's University collaborative project. We thank Ms. O. Donini for assistance with operational aspects of parallel GAUSSIAN 94, and the Natural Sciences and Engineering Research Council of Canada (NSERC) for financial support. We also gratefully acknowledge the use of the SGI computing installation in the Geochemistry Labs at McMaster funded by NSERC. 


\section{References}

1. V. Somayaji and R.S. Brown. J. Org. Chem. 51, 2676 (1986).

2. Q.-P. Wang, A.J. Bennet, R.S. Brown, and B.D. Santarsiero. J. Am. Chem. Soc. 113, 5757 (1991).

3. N.H. Werstiuk, D.N. Butler, and E. Shahid. Can. J. Chem. 65, 760 (1986)

4. W.J. Hehre, L. Radom, P.v.R. Schleyer, and J.A. Pople. Ab initio molecular orbital theory. John Wiley \& Sons, New York. 1986.

5. A.D. Becke. J. Chem. Phys. 98, 5648 (1993); C. Lee, W. Yang, and R.G. Parr. Phys. Rev. B: Condens. Matter, 37, 785 (1988).

6. M.J. Frisch, G.W. Trucks, M. Head-Gordon, P.M.W. Gill, M.W. Wong, J.B. Foresman, B.G. Johnson, H.B. Schlegel, M.A. Robb, E.S. Replogle, R. Gomperts, J.L. Andres, K. Raghavachari, J.S. Binkley, C. Gonzalez, R.L. Martin, D.J. Fox, D.J. Defrees, J. Baker, J.J.P. Stewart, and J.A. Pople. Gaussian 92. Gaussian, Inc., Pittsburgh, Pa. 1992.

7. M.J. Frisch, G.W. Trucks, H.B. Schlegel, P.M.W. Gill, B.G. Johnson, M.A. Robb, J.R. Cheeseman, T. Keith, G.A. Petersson, J.A. Montgomery, K. Raghavachari, M.A. Al-Laham, V.G. Zakrzewski, J.V. Ortiz, J.B. Foresman, C.Y. Peng, P.Y. Ayala, W. Chen, M.W. Wong, J.L. Andres, E.S. Replogle,
R. Gomperts, R.L. Martin, D.J. Fox, J.S. Binkley, D.J. Defrees, J. Baker, J.P. Stewart, M. Head-Gordon, C. Gonzalez, and J.A. Pople. Gaussian 94, Revision B.3. Gaussian, Inc., Pittsburgh, Pa. 1995.

8. V. Somayaji, K.I. Skorey, R.S. Brown, and R.G. Ball. J. Org. Chem. 51, 4866 (1986).

9. Q. Wang, A.J. Bennet, R.S. Brown, and B.D. Santarsiero. Can. J. Chem. 68, 1732 (1990).

10. L. Åsbrink, C. Fridh, and E. Lindholm. HAM/3. QCPE Bull. 13, 393 (1981).

11. R. Sustmann and W. Sicking. Chem. Ber. 120, 1323 (1987).

12. A.J. Arduengo III, H. Bock, H. Chen, M. Denk, D.A. Dixon, J.C. Green, W.A. Herrmann, N.L. Jones, M. Wagner, and R. West. J. Am. Chem. Soc. 116, 6641 (1994).

13. K.B. Wiberg and C.M. Breneman. J. Am. Chem. Soc. 114, 831 (1992).

14. J.P. Maier and D.W. Turner. J. Chem. Soc. Faraday Trans. 2, 69, 521 (1973).

15. T. Koopmans. Physica, 1, 104 (1933).

16. R.F.W. Bader. Atoms in molecules. A quantum theory. Clarendon Press, Oxford. 1990.

17. L. Treschanke and P. Rademacher. J. Mol. Struct. (Theochem), 122, 35 (1985). 